\title{
Behavioural and vocal responses in Canis Lupus in response to transposed playbacks
}

N Wheadon, R Morgan, J C Litten-Brown

School of Agriculture, Policy and Development, Reading University, Reading, United Kingdom

Email:r.morgan@reading.ac.uk

Introduction Stimulating wolves (Canis Lupus) to get initial howls of choruses can be a method of detecting information about pack identity (Harrington, 1989) and give estimates of numbers within the pack to help decide on conservation status. This study examined the effect of pitch of transposed playbacks on wolf behavioural and vocal reactions and whether age or gender affected the response.

Materials and methods Responses of six wolves from two packs (North American and Juvenile packs) at the Wolf Conservation Trust, Berkshire, UK were recorded 10 seconds after ending playback of a pre-recorded howl track (Wolf Howl Animal Preserve LLC, Mississippi, America). Each track was transposed using Ableton Live 7.0 and ranged from 6st- (very low pitched) to 6st (high pitched) at intervals of 2st. Four different tracks of 45 seconds were used in a repeated measures design, played either high to low, or low to high, weekly over an 8 week period. A 10 minute refractory period was left between each track to allow the wolves to return to normal behaviours. Responses were graded using the following scale. $1=$ no response, $2=$ eye contact, $3=$ ear twitching, $4=$ head up/noticeable looking, $5=$ sniffing, $6=$ get up, $7=$ movement towards the sound or purposefully away, $8=$ whimper/yip/bark or whine, $9=$ short or quiet howl, $10=$ long or loud howl. Data were analysed using Minitab ${ }^{\odot}$ v15 ANOVA GLM.

Results Transpose level did not have a significant effect on the behavioural and vocal responses of the wolves (Table 1). However gender $(\mathrm{P}<0.001$; Figure 1$)$ and age $(\mathrm{P}<0.001$; figure 2$)$ had significant effects.

Table 1 Effect of transpose level on response

\begin{tabular}{|c|c|c|c|c|c|c|c|c|}
\hline & \multicolumn{8}{|c|}{ Transpose level } \\
\hline & $6 \mathrm{st}$ & $4 \mathrm{st}$ & $2 \mathrm{st}$ & 0st & 2st- & 4st- & 6 st- & Pooled SEM \\
\hline Behavioural response (least square means) & 3.53 & 3.56 & 2.75 & 2.53 & 2.84 & 2.66 & 2.59 & 0.380 \\
\hline
\end{tabular}

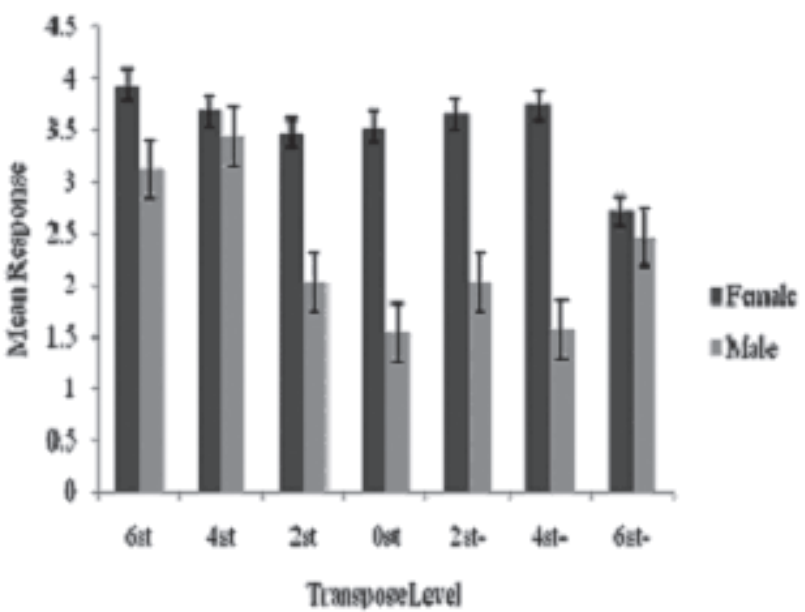

Figure 1 Effect of gender on response

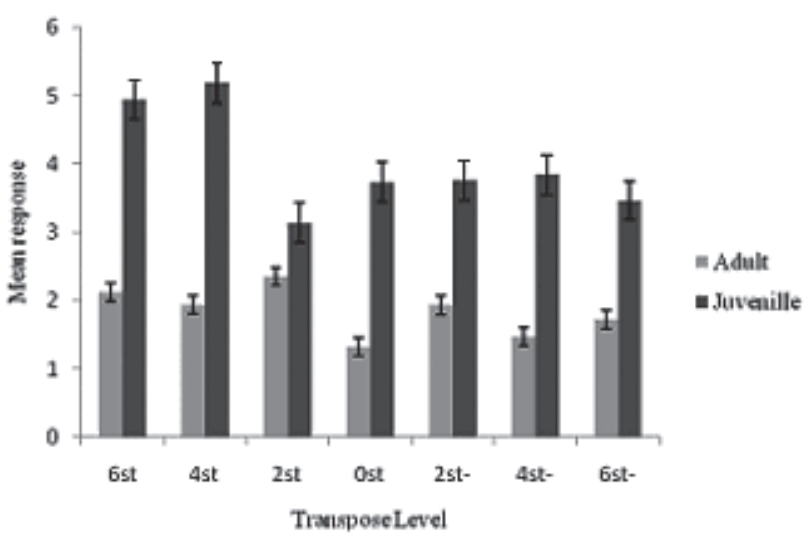

Figure 2 Effect of age on response

Conclusions Gender and age had pronounced effects on whether wolves would respond to playback experiments. Females responded better than males to the playback tracks, in contrast to the findings of Harrington and Mech (1979) where alpha males demonstrated the greatest response. Younger wolves appeared to respond better than adults which may be helpful in determining breeding numbers in a chosen area. This could be due to juveniles being more inquisitive, active and having better hearing (Fogle, 1990). Individual differences in response may be dependent on the context of the sound and this should be taken into account when choosing the meaning of the tracks chosen to use. The findings indicate that tracking and locating wolves in the wild is possible using playbacks; and gender and age affect response, however the optimal pitch to use needs to be investigated further.

Acknowledgements Dr. Darren Juniper and Kirsty Kliem, University of Reading, for advice and help on the completion of the statistical analysis and staff at the Wolf Conservation Trust, Berkshire, UK for help and loan of the wolves.

\section{References}

Fogle, B. 1990. The dogs mind. England. Penguin Group.

Harrington, F. H. and Mech, D. L. 1979. Wolf howling and its role in territory maintenance. Behaviour 68, $207-249$. Harrington, F. H. 1989. Chorus howling by wolves: acoustic structure, pack size and the Beau Geste effects. Bioacoustics 2, 117-136. 